\title{
Desenvolvimento rural e agricultura familiar: um estudo do Projeto de Assentamento Dirigido Humaitá - Porto Acre (AC)
}

\author{
RAIMUNDO CLÁUDIO GOMES MACIEL \\ Universidade Federal do Acre
}

REGINALDO SILVA MARIANO

Universidade Federal do Acre

PEDRO GILBERTO CAVALCANTE FILHO

Universidade Federal do Acre

\begin{abstract}
Resumo
Em uma tentativa de minimizar os efeitos negativos da questão agrária o Governo vem implantando ferramentas que possam solucionar o problema agrário, como o Estatuto da Terra e a criação do Instituto Nacional de Colonização e Reforma Agrária-INCRA. Neste processo foram instituídos mecanismos do modelo da reforma agrária, onde se encontram 20 tipos de assentamentos como os Projetos de Assentamentos Dirigidos-PADs. Este trabalho tem como objetivo avaliar o Projeto de Assentamento Dirigido Humaitá localizado no município de Porto Acre - AC. Para isso, se utiliza uma análise da dinâmica do Índice de Desenvolvimento Familiar Rural-IDF-R no período de 2005/2006 e 2012/2013. Esse índice permite encontrar as condições de vida do produtor familiar rural, abordando dimensões de seu cotidiano e comparando ambos os períodos. Os resultados indicam que o tão almejado desenvolvimento rural não foi alcançado pelas unidades de produção familiar do Humaitá.

Palavras-chaves: Desenvolvimento Rural. Reforma Agrária. Agricultura Familiar.
\end{abstract}

Rural development and family agriculture: a study of the Humaitá Directed Sealing Project - Porto Acre (AC)

\begin{abstract}
In order to minimize the negative effects about agrarian matter, the Government has been implementing mechanisms to solve the agrarian problem, for example, the Land Statute and the foundation of the Agrarian Colonization and Reformation National Institute (INCRA). At this process, mechanisms of agrarian reform model were instituted, as can be identified 20 types of settlements, such as the Managed Settlement Projects (PAD). This
\end{abstract}


study aims to evaluate the Humaita Managed Settlement Project, located in Porto Acre AC. For this, it uses an analysis of the dynamics of the Rural Family Development Index (IDF$R$ ) in the periods $2005 / 2006$ and 2012/2013. The IDF-R allows finding the living conditions of the rural family farmers, approaching dimensions of their daily lives and comparing both periods. The results presented that the Humaita's familiar production units did not achieve the so coveted rural development.

Keywords: Rural Development. Agrarian Reform. Family Farming.

\title{
Desarrollo rural y agricultura familiar: un estudio del Proyecto de Asiento Dirigido Humaitá - Porto Acre (AC)
}

\begin{abstract}
Resumen
En un intento de minimizar los efectos negativos de la cuestión agraria el Gobierno viene implantando herramientas que puedan solucionar el problema agrario, como el Estatuto de la Tierra y la creación del Instituto Nacional de Colonización y Reforma Agraria (INCRA). En este proceso fueron instituidos mecanismos del modelo de la reforma agraria, donde se encuentran 20 tipos de asentamientos como los Proyectos de Asentamientos Dirigidos (PAD). Este trabajo tiene como objetivo evaluar el Proyecto de Asentamiento Dirigido Humaitá ubicado en el municipio de Porto Acre - AC. Para ello, se utiliza un análisis de la dinámica del Índice de Desarrollo Familiar Rural (IDF-R) en el período 2005-2006 y 2012/2013. El IDF-R permite encontrar las condiciones de vida del productor familiar rural, abordando dimensiones de su cotidiano y comparando ambos períodos. Los resultados indican que el tan anhelado desarrollo rural no fue alcanzado por las unidades de producción familiar del Humaitá.
\end{abstract}

Palabras claves: Desarrollo Rural. Reforma agraria. Agricultura familiar.

\section{Introdução}

A questão agrária no Brasil sempre foi um ponto de grande discussão, não só do ponto da distribuição das terras, mas também do ponto que tange o papel da agricultura familiar como forma de desenvolvimento rural e sustentável, promovendo a qualidade de vida e renda das famílias no campo.

Dentre as políticas públicas que visam promover a reforma agrária e o desenvolvimento rural e sustentável estão os projetos de assentamentos criados pelo Instituto Nacional de Colonização e Reforma Agrária-INCRA, como o Projeto de Assentamento Dirigido- PAD. O grande objetivo é promover o desenvolvimento rural por meio da agricultura familiar. Porém, as contradições e a realidade no campo mostram que, ao longo do tempo, em muitos projetos há uma redução da agricultura familiar, bem como uma diminuição da qualidade de vida dessas famílias.

Assim, dentro dessa discussão, o presente trabalho tem como objetivo analisar e comparar o índice de desenvolvimento familiar rural das famílias assentadas no PAD Humaitá, criado em 1981, localizado no Município de Porto Acre AC, baseando-se nos levantamentos dos períodos de 2005/2006 e 2012/2013.

Primeiramente, para tanto, é feita uma conceituação teórica sobre agricultura familiar, reforma agrária e desenvolvimento rural. Posteriormente, discute-se acerca dos conceitos de desenvolvimento, desenvolvimento sustentável, e do Índice de Desenvolvimento da Família-IDF. Por fim, apresenta-se a análise dos 
Desenvolvimento rural e agricultura familiar: um estudo do Projeto de Assentamento Dirigido Humaitá - Porto Acre (AC)

resultados obtidos dos levantamentos realizados junto às famílias da região, procurando fazer a comparação do IDF-R entre os períodos citados.

\section{Caracterização da agricultura familiar e Reforma Agrária no Brasil}

Para discutir e analisar o conceito de agricultura familiar, é necessário definir agricultura de forma geral. Para George (1975, p. 9) apud Simoura (2013, p. 18), a agricultura era "uma domesticação das plantas e animais úteis ao homem". No entanto, esta definição foi evoluindo com o passar dos anos até chegar a conceitos mais amplos, como o apresentado por Lima Junior (2013, p. 18), que diz:

[...] a agricultura se compreende como a atividade produtiva integrante do setor primário da economia, que é caracterizada através da produção de bens alimentícios e matérias primas decorrente do cultivo de plantas e da criação de animais.

Segundo o autor, a atividade agrícola tem uma divisão de acordo com a importância de cada fator a ser empregado na sua produção. A ocorrência do capital como fator primordial denomina-se agricultura intensiva. Entretanto, quando o fator essencial é a terra, denomina-se agricultura extensiva. Este ocorre principalmente nos países subdesenvolvidos, e aquele acontece nos países desenvolvidos.

$\mathrm{Na}$ atualidade, o incremento da agricultura intensiva, principalmente nos países desenvolvidos, e a não disseminação equitativa da mesma, foi o motivo do surgimento de conceitos de agricultura familiar nos países subdesenvolvidos. A agricultura familiar ou produção familiar é uma forma de organização social da produção na qual a própria família tem a posse dos meios de produção, além de engendrar o processo produtivo (MACIEL, 2010). Esta atividade visa à satisfação imediata da unidade de produção, ou seja, o consumo imediato dos bens produzidos, havendo a reprodução simples do capital, sem expandir os meios de produção da unidade.

No Brasil, o conceito de agricultura familiar ganhou bastante representatividade do ponto de vista produtivo. Isso porque é ela a responsável por boa parte do que vem das áreas rurais em termos de produção de bens consumidos nas cidades. Devido a sua importância, Kageyama e Bergamasco (1990) apud Oliveira e Duarte (2008) estabelecem uma conceituação e categorização de produtores familiares, no Brasil, por meio dos seguintes aspectos:

a) O gerenciamento da produção familiar e os investimentos inclusos são postos em prática pelos componentes da unidade produtiva que têm entre si algum grau de parentesco ou de matrimônio;

b) $\quad 0$ trabalho relativo à produção familiar rural origina-se de forma equitativa pelos membros familiares;

c) A família é a proprietária dos meios de produção (às vezes, com exceção da posse da terra, que pode ser arrendada, em forma de concessão ou outro tipo de transferência do uso da terra), que pode ser repassada aos outros parentes, por motivo de morte ou aposentadoria. (FAO/INCRA, 1996 apud COSTABEBER e CAPORAL, 2003, p. 11). 
Depois de estabelecer os parâmetros que definem de maneira mais detalhada o agricultor familiar, pode-se analisar as proporções desta atividade no Brasil. De acordo com a Salles Souza e Moura (2002) apud Simoura (2013), as áreas destinadas à produção familiar rural perfazem um total de $30 \%$ das zonas rurais destinadas à agricultura. Nesse contexto, o País vive uma política estatal de desenvolvimento, considerando rural claramente com duas vertentes, conforme afirma Fonseca e Fagnani (2013), de um lado se tem como principal política os agronegócios e de outro, a agricultura familiar.

Apesar desse papel secundário, a agricultura familiar, segundo o Censo Agropecuário de 2006 (IBGE, 2009 apud Fonseca e Fagnani, 2013) detém 84,4\% dos estabelecimentos agropecuários que corresponde em números absolutos, a 4.367.902 unidades. Outro papel dado à agricultura familiar, além da produção de alimentos, foi o combate à pobreza rural. Diversos programas governamentais objetivam a erradicação desses males no campo.

A principal política adotada para promover melhorias de vida no campo é a reforma agrária. Para definir e entender melhor essa política, é preciso fazer uma análise da contextualização sobre a questão agrária. A questão agrária faz referência à relação da pecuária e a agricultura como meio em que se localiza, através da utilização da terra, demonstrando as correlações sociais, culturais e econômicas de forma geral.

O tema agrário é fortemente debatido no âmbito brasileiro, onde o Estado vem criando mecanismo e ferramentas para resolver em definitivo problemas sociais, econômicos, e porque não dizer, ambientais. Observa-se, por exemplo, o surgimento do Estatuto da Terra e a criação do INCRA.

Essas discussões sobre a questão agrária geram a necessidade de debater temas como a reforma agrária. Esta faz referência a uma mudança do agrário, quer seja na estrutura, quer seja em sua composição e distribuição espacial. Esse processo de mudança se dá de diversas formas e essas formas evoluem de acordo com o tempo de seu enfoque, como afirma Alentejano (1996) apud Olalde e Portugal (2004). Pode ser uma divisão das abordagens sobre a Reforma Agrária nos anos 1990: a) Reforma Agrária enquanto política social compensatória; b) Reforma Agrária com função de política distributiva; e, por fim, c) Reforma Agrária tendo o papel de política com o intuito de transformar o modelo de desenvolvimento atual.

Por outro lado, Fernandes (2006) afirma que o descaso desta população pela falta de políticas públicas voltadas a este setor, relacionou os agricultores familiares a palavras depreciativas, de forma que eram considerados como ociosos e com pouca disposição ao trabalho. No entanto, a produtividade da agricultura familiar, há uma década, demonstra mudanças culturais, sociais e políticas, comparando aos anos 1970. As iniciativas políticas têm contribuído para o desenvolvimento das regióes rurais, buscando um novo formato para este meio, respeitando e ajustando cada região de acordo com sua realidade no que se alicerça a agricultura familiar. $\mathrm{Na}$ década de 1990, foram criadas políticas e instituições voltadas para o fortalecimento desse público, como o Programa de Fortalecimento da Agricultura Familiar-PRONAF e o Ministério de Desenvolvimento Agrário-MDA. Todas essas mudanças foram resultados das reivindicações dos produtores rurais e grupos sociais organizados ligados à discussão da reforma agrária no Brasil. 
Desenvolvimento rural e agricultura familiar: um estudo do Projeto de Assentamento Dirigido Humaitá - Porto Acre (AC)

\section{Desenvolvimento, Desenvolvimento Sustentável e Índice de Desenvolvimento da Família}

Ao iniciar o debate sobre o tema desenvolvimento, faz-se necessário uma diferenciação conceitual do que vem a ser crescimento e desenvolvimento, pois existe alguma confusão conceitual entre esses dois temas.

Crescimento refere-se à renda de um país propriamente dita, do ponto de vista do que é produzido em determinado país num período de tempo, podendo ser medido por meio do Produto Interno Bruto-PIB.

A diferenciação entre crescimento e desenvolvimento fica mais clara nas palavras de Furtado (1967, p. 74-76) apud Bresser-Pereira (2008, p. 3), quando diz que "o desenvolvimento compreende a ideia de crescimento, superando-a". Segue dizendo que "o crescimento é o aumento da produção, ou seja, do fluxo da renda, ao nível de um subconjunto especializado, e o desenvolvimento é o fenômeno do ponto de vista de suas repercussões no conjunto econômico de estrutura complexa que inclui o anterior".

O conceito de desenvolvimento econômico na visão de Bresser-Pereira (2008) deduz uma sociedade capitalista organizada na maneira de um Estadonação, existindo empresários e trabalhadores, lucros e salários, acumulação de capital e progresso técnico, um mercado ordenando o sistema econômico e um estado regulador desse mercado, completando sua função de ordenador.

Sobre a difusão do desenvolvimento econômico durante a década de 1970, praticado por países ditos ricos ou de primeiro mundo, havia duras críticas na adoção desse modelo propalado nos países pobres ou de terceiro mundo, sendo um dos grandes críticos Celso Furtado, com sua abordagem sobre o Mito do Desenvolvimento. Inicialmente, Furtado (1974) apud Plein e Filippi (2012), critica a ideia de que o desenvolvimento econômico que vinha sendo utilizado nos países líderes da revolução industrial poderia ser universal, isto é, a forma de consumo dos habitantes dos países ricos seria acessível à grande população crescente residente nos países pobres.

A intenção primeira do desenvolvimento econômico visa a alcançar o objetivo político principal das sociedades modernas que vem a ser o bem estar, e de forma indireta, os outros quatro grandes objetivos buscados pelas sociedades modernas, que são: a segurança, liberdade, justiça social e a proteção do ambiente.

O Programa das Nações Unidas para o Desenvolvimento-PNUD aceita que o Índice de Desenvolvimento Humano-IDH é um marco. O IDH teve sua criação com o intuito de embasar empiricamente os Relatórios de Desenvolvimento Humano, publicado pela Organização das Nações Unidas-ONU, sendo que esses relatórios serviam para acompanhar o processo de desenvolvimento mundial naquele período (IPEA, 1998). Entretanto, o PNUD lembra que o processo de desenvolvimento é bem mais abrangente e contém muita complexidade do que qualquer forma de mensuração sumária pudesse identificar, mesmo quando complementada com outros índices.

Furtado (2004) revela que crescimento econômico vem se transformando na preservação de privilégios das classes dominantes, enquanto que 0 desenvolvimento detinha aspectos de um projeto social implícito, isto é, desenvolvimento econômico resultaria em distribuição de renda. 
No tocante à dicotomia entre desenvolvimento com distribuição equitativa de renda e crescimento com exclusão social, é interessante se deter na afirmativa de Sachs (2004, p.38) apud Bresser-Pereira (2008), de que existe um desenvolvimento includente e um crescimento que exclui ou que concentra. 0 crescimento econômico tem características perversas que alijam do mercado de consumo e concentra a renda e a riqueza. Já o desenvolvimento econômico, político, social e autossustentável pode se definir como desenvolvimento humano, corroborado na existência do IDH.

Por outro lado, com as questões ambientais sendo debatidas mais intensamente, na década de 80 , origina-se o conceito de sustentabilidade, por meio de estudos da ONU, com foco nas mudanças climáticas como uma forma de resposta acerca da crise social e ambiental observada no mundo a partir da segunda metade do século XX (BARBOSA, 2008).

No que se refere aos objetivos do desenvolvimento sustentável, por meio da Carta de Ottawa (1986), foram relacionados alguns desses possíveis objetivos como, tais como: integração da conservação e do desenvolvimento; satisfação das necessidades básicas humanas; alcance de equidade e justiça social; provisão da autodeterminação social e da diversidade cultural; manutenção da integração ecológica.

Aceita-se como conceito de desenvolvimento sustentável sendo "aquele que satisfaz as necessidades do presente sem comprometer a capacidade das gerações futuras", divulgado em 1987, originado da Assembleia Geral das Nações Unidas (Brasil, 2004, p. 7 apud BRITO, 2013, p. 49), indicando compatibilidade social entre o crescimento econômico e o ambiental, preservação ambiental e equidade social.

O desenvolvimento sustentável deve se caracterizar como sendo um processo de mudanças, com a interação entre a exploração dos recursos, o gerenciamento de investimento tecnológico e as alterações institucionais com o passar do tempo (CANEPA, 2007 apud BARBOSA, 2008).

Por fim, o desenvolvimento sustentável deve ser um processo de aprendizagem social de longo prazo, onde é direcionado por políticas públicas direcionadas por um plano de desenvolvimento nacional (BEZERRA e BURSZTYN, 2000 apud BARBOSA, 2008).

Em relação a essa questão de sustentabilidade, esse amplo conceito é atrelado a diversas áreas como ao meio rural. Para a devida compreensão do que vem a ser "desenvolvimento rural", é preciso definir desenvolvimento agrícola e desenvolvimento agrário. Segundo Navarro (2001), desenvolvimento agrícola ou agropecuário refere-se às condições da produção agrícola e/ou agropecuária no sentido produtivo, identificando suas tendências em um determinado lapso temporal. No tocante ao desenvolvimento agrário, Navarro (2001) enfatiza que o conceito está ligado à interpretação do "mundo rural" em suas relações com a sociedade como um todo, em todas as suas dimensões, e não apenas à estrutura agrícola.

Com isso, tem-se que o desenvolvimento rural, para Navarro (2001, p. 88):

diferencia-se dos anteriores por uma característica específica: tratando de uma ação previamente articulada que induz (ou pretende induzir), mudanças em um determinado ambiente rural. Em consequência, 0 Estado Nacional - ou em seus níveis subnacionais - sempre esteve 
Desenvolvimento rural e agricultura familiar: um estudo do Projeto de Assentamento Dirigido Humaitá - Porto Acre (AC)

presente à frente de qualquer proposta de desenvolvimento rural, como seu agente principal.

O modelo de desenvolvimento rural adotado no Brasil foi implantado por meio das chamadas Políticas de Desenvolvimento Rural Integrado-PDRI. Este modelo tinha características produtivistas, conforme afirma Weisheimer (2013), que fizeram com que houvesse um esgotamento prematuro dos solos, bem como a contaminação dos recursos hídricos, e ainda fez aparecer a figura do desmatamento nas áreas de florestas tropicais.

A partir da década de 1990, a visão a respeito do desenvolvimento rural mudou de direção, devido aos novos rumos que foram influenciados pelas mudanças do ponto de vista social, político e econômico do Estado, da sociedade e dos pensadores da academia. Assim, o desenvolvimento rural propiciou políticas governamentais nas áreas da reforma agrária, no crédito ao agricultor familiar, no apoio à zona rural, e em políticas inclusivas direcionadas às mulheres, aos jovens, aos aposentados e, por fim, aos negros. (SCHNEIDER, 2010)

\section{5 Índice de Desenvolvimento da Família e Distribuição de Renda}

O Instituto de Pesquisa Econômica Aplicada-IPEA criou o IDF como forma de complementar e ampliar o alcance na avaliação do desenvolvimento de uma localidade por meio da mensuração do desenvolvimento de suas famílias. O IDF considera seis dimensões, 26 componentes e 48 indicadores, com uma maior abrangência que o IDH. Com isso, tem-se a maior probabilidade de se obter um diagnóstico mais próximo da realidade.

A composição das seis dimensões relativas às condições de vida sintetizadas pelo IDF é: a) ausência de vulnerabilidade; b) acesso ao conhecimento; c) acesso ao trabalho; d) disponibilidade de recursos; e) desenvolvimento infantil; e f) condições habitacionais (IPEA, 1998).

O IDF tem uma estreita relação com a distribuição de renda, a desigualdade de renda e social e a pobreza. Todos esses temas combinados resultam no baixo IDF, o que mostra essa questão intimamente relacionada com o desenvolvimento econômico dos países, isso é, a forma com que a renda nacional é distribuída, causando a existência ou não da pobreza.

Há que se fazer uma diferenciação conceitual entre desigualdade de renda e distribuição de renda, pois o primeiro conceito tem a ver com as chamadas classes sociais ( $A, B, C, D, E$, tendo como parâmetro as faixas salariais). Enquanto que ao segundo conceito se relaciona com a forma que é distribuída a renda, causando concentração ou não de renda (IPEA, 2013).

Uma das possíveis causas da enorme e crescente má distribuição de renda brasileira, e comumente observada nos países latino-americanos, decorre do passado desses países, mais precisamente nos processos de formação e evolução do ponto vista socioeconômico, haja vista que foram colônias portuguesas e espanholas (HOFFMANN, 2001).

Segundo Hoffmann (2001), uma das grandes certezas que se tem quando se fala em aumento da desigualdade de renda é a participação efetiva do fator inflação elevada. É ponto pacífico que o processo de crescimento de um país é afetado pelo tipo de distribuição de renda. 
Para Santos e Dulci (2008), o papel das transferências de rendas estatais na diminuição da má distribuição de renda, remonta dos tempos do final dos feudos. Entretanto, tomou corpo com o advento do modelo de gestão nacional baseado no Estado do Bem-estar.

O papel do governo é preponderante para resolver o problema da distribuição de renda de um país, podendo ocorrer por meio de seus instrumentos de intervenção, na avaliação de Hoffmann (2001), como é o caso das seguintes políticas: fiscal, previdência social, de crédito, de reforma agrária e educacional. Esta última influencia sobremaneira a aceleração do crescimento econômico, com a elevação da qualidade educacional e seu alcance populacional, fazendo com que haja, consequentemente, uma diminuição na distribuição de renda injusta.

Assim, um aspecto relevante da distribuição de renda nos países pobres ou em desenvolvimento é a elevada desigualdade de renda, causada por diversos fatores, dentre eles, a elevada concentração de renda.

No âmbito mundial, o Brasil possui uma das maiores desigualdades de rendas do mundo, é o que comenta Ferreira (2003) apud Lima (2013, p. 5), quando diz que "o Brasil continua ocupando posição de destaque internacional como uma das sociedades mais desiguais do planeta [...] O Coeficiente de Gini para distribuição de renda total familiar per capita permaneceu na média de 0,59".

A íntima relação entre a desigualdade na distribuição de renda e a elevada presença de pobreza no Brasil é afirmada também por Barros (2001) apud Lima (2013), que diz que a perversa desigualdade de renda e alternativas de inclusão socioeconômica tem na figura da maioria pobre da população brasileira seu maior aspecto determinante.

Vale ressaltar que, nessa discussão, deve-se diferenciar os conceitos de desigualdade e pobreza, conforme deixa claro Ribeiro (2009 p.20) apud Lima (2013), quando afirma que a principal característica da desigualdade reside na má distribuição dos recursos nacionais entre suas classes, enquanto que, na pobreza, os fatores determinantes são a escassez do produto e a péssima distribuição de renda, que, consequentemente, reflete no não atendimento das necessidades básicas da população.

Dentre os vários efeitos resultantes da desigualdade de renda, está a elevação do descontentamento social, que por si acarreta instabilidade política, que, por sua vez, faz surgir uma incerteza político-econômica, que, por fim, traz a redução do nível de investimento e do crescimento, pois este cenário afugenta os recursos externos provenientes de investidores (ALESINA e PERROTI, 1993 apud ALVAREZ, 1996)

É possível fazer uma correlação entre um elevado grau de desigualdade de renda e a taxa de crescimento do PIB e com a taxa de inflação dos países (BONELLI e RAMOS, 1993 apud ALVAREZ, 1996).

Os mesmos autores apontam para uma interação de forma positiva entre a taxa de inflação e a desigualdade, e por outro lado, a existência de uma relação negativa observada entre o crescimento econômico e a concentração de renda.

Dessa forma, desperta-se a atenção para a desigualdade social, que está correlacionada com distribuição de renda e desigualdade de renda, pois torna-se uma reação em cadeia, já que, quando se tem uma má distribuição de renda, ocorre a desigualdade de distribuição de renda, que resulta numa desigualdade social. 
Desenvolvimento rural e agricultura familiar: um estudo do Projeto de Assentamento Dirigido Humaitá - Porto Acre (AC)

Assim, a desigualdade social pode ser caracterizada por meio de diversos fatores, conforme a afirmativa de Filho e Guzzo (2009), que explana sobre a influência da concepção de viver, morar, os relacionamentos, o tipo de vestuário, dentre outros aspectos. Outro medidor que pode ser utilizado para mensurar a desigualdade é o fator econômico.

Diante da desigualdade social, é elencado o debate sobre pobreza. Segundo Rocha (2006), pobres são aqueles indivíduos que têm a renda familiar per capita menor do que o valor correspondente ao que seria preciso para atender às necessidades básicas, tais como: alimentação, habitação, transporte, saúde, lazer, educação, dentre outros.

Ainda sobre a definição de pobreza, comentam Barros, Henriques e Mendonça (2001), que ela não pode ser definida única e universalmente, pois ela se refere a situações de carência em que os indivíduos não conseguem manter um padrão mínimo de vida de acordo com as referências socialmente estabelecidas em cada contexto histórico.

Para a definição de pobreza, é imprescindível traçar um limitador, isto é, uma linha de pobreza, podendo indicar se esta pobreza é relativa ou absoluta.

Outra definição comumente aceita e difundida amplamente é a que relaciona renda per capita e linha de pobreza. Conforme Vilela (2010), pobres são aqueles indivíduos cujas famílias detêm renda per capita abaixo da linha de pobreza.

Com relação às políticas de combate à pobreza, por conseguinte à desigualdade, conforme a Universidade Virtual Brasileira-UVB (2009) reside na figura do surgimento de oportunidades, decorrentes de uma educação de qualidade.

No que se refere à situação da pobreza rural, observa-se que está havendo uma diminuição no quantitativo de pobres, bem como na desigualdade econômica, levando-se a crer que está ocorrendo uma modificação na pobreza rural em relação ao seu perfil e a sua dinâmica reprodutiva (BUAINAIN et al., 2012).

\section{Metodologia}

Este trabalho tem como objeto de estudo a análise da dinâmica do Índice de Desenvolvimento Familiar Rural-IDF-R do Projeto de Assentamento Dirigido-PAD Humaitá, no período de 2005/2006 a 2012/2013.

O Projeto de Assentamento Dirigido-PAD Humaitá foi criado em 08 de agosto de 1981, através da Resolução 117 do INCRA. O PAD Humaitá abrange uma área de 63.861 ha. A área localiza-se no Município de Porto Acre, distante 30 quilômetros da capital Rio Branco. É tangenciado por uma rodovia federal, a BR 317, sendo diretamente ligado pela rodovia $A C 10$, possuindo uma via de acesso natural, que é o rio Acre, importante via de escoamento da produção agrícola familiar para os produtores que residem na região banhada por esse rio (SOUZA, 2000, p.17 apud MACIEL et al, 2008). 
Para realizar a avaliação socioeconômica da produção familiar rural no assentamento Humaitá, utilizar-seá a metodologia do Projeto de Pesquisa Análise Socioeconômica de Sistemas de Produção Familiar Rural no Estado do Acre-ASPF 1 , desenvolvido pelo Centro de Ciências Jurídicas e Sociais Aplicadas-CCJSA da Universidade Federal do Acre-UFAC desde 1996.

A metodologia emprega medidas de resultado econômico, que se constituem em indicadores/índices que, dados os custos de produção, permitem medir o desempenho econômico do sistema de produção, como também índices de desenvolvimento rural. As principais medidas são as seguintes:

1) Renda Bruta-RB: indicador de escala de produção.

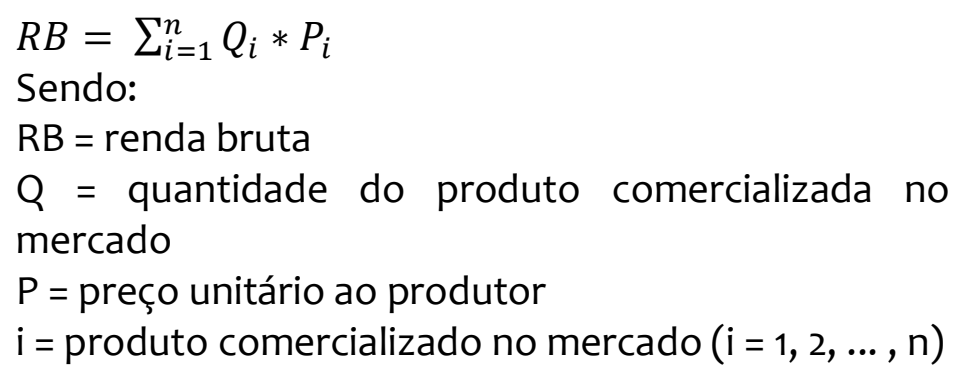

2) Renda Bruta Total-RBT: resultado do somatório da Renda Bruta-RB da produção com a renda oriunda das transferências de renda e do assalariamento fora da UPF.

$$
R B T=R B+R T+R A
$$

Sendo:

$\mathrm{RB}=$ renda bruta;

$\mathrm{RT}$ = renda das transferências monetárias (municipal, estadual e federal)

RA = renda de assalariamento fora da Unidade Padrão

Fisdcal-UPF

3) Renda Líquida-RL: é o valor excedente apropriado pela unidade de produção familiar.

$$
\begin{aligned}
& \mathrm{RL}=\mathrm{RB}-\mathrm{DE} \\
& \text { Sendo, } \\
& \mathrm{RL}=\text { renda líquida } \\
& \mathrm{RB}=\text { renda bruta } \\
& \mathrm{DE}=\text { despesas efetivas }
\end{aligned}
$$


Desenvolvimento rural e agricultura familiar: um estudo do Projeto de Assentamento Dirigido Humaitá - Porto Acre (AC)

4) Margem Bruta Familiar-MBF: valor monetário disponível para a família.

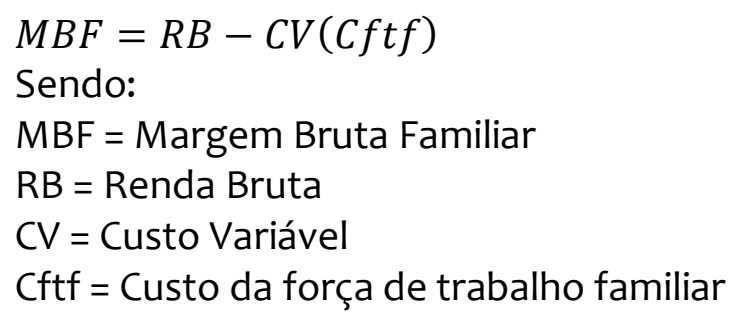

5) Autoconsumo-AC: bem produzido e consumido pela própria família.

$A C=\sum_{i=1}^{n} Q b c p_{i} * P_{i}$

Sendo:

$\mathrm{AC}=$ Autoconsumo;

Qbcp = Quantidade do bem de autoconsumo produzido

$\mathrm{P}=$ preço unitário do bem de autoconsumo produzido

$i=i$ tens de bens de autoconsumo produzidos $(i=1,2, \ldots, n)$

6) Índice de Eficiência Econômica-IEE: indicador de benefício/custo.

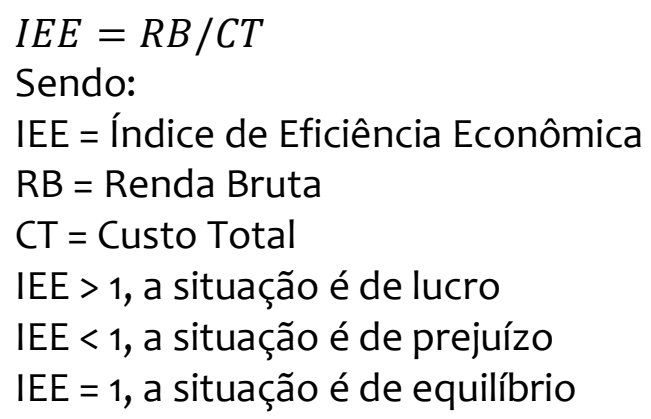

7) Nível de Vida: o valor que determina o padrão de vida da família

$N V=(M B F+A C+C j i c c)-A A$

Sendo:

Cjicc = juros imputados ao capital circulante

Na metodologia utilizada pelo ASPF, tem-se a seguinte configuração quanto ao Índice de Desenvolvimento Familiar Rural-IDF-R:

$$
\begin{array}{ll}
1 \text { - IDF- } R \text { ruim: } & 0,00<\text { IDF- } R<0,25 \\
\text { - - IDF-R regular: } 0,25<\text { IDF- } R<0,50 \\
\text { 3- IDF- } R \text { bom: } \quad 0,50<\text { IDF- } R<0,75 \\
\text { 4- IDF- } R \text { ótimo: } \quad 0,75<\text { IDF- } R<1,00
\end{array}
$$

O IDF-R tem seu intervalo de 0 a 1, onde em um cenário mais próximo de 1, denota que as condições de vida são próximas de uma padrão de vida ideal, e o contrário é verdadeiro, isto é, mais próximo de o significa um cenário caótico, de 
pobreza extrema.

Segue abaixo a fórmula e as variáveis componentes do IDF-R, segundo as dimensões mencionadas:

$I D F-R=(I V+I E+I C+I T+I R+I D+I H+I A) / 8$

Em que,

O índice de ausência de vulnerabilidade-IV é composto pelas variáveis: fecundidade, idosos, dependência econômica, presença dos pais e será calculado pela fórmula:

$I V=\left[\left(V_{1}+V_{2}+V_{3}+V_{4}+V_{5}\right) / 5+\left(V_{6}+V_{7}\right) / 2+V_{8}+\left(V_{9}+V_{10}\right) / 2\right] / 4$

Sendo,

Quadro 1. Indicadores de Ausência de Vulnerabilidade

\begin{tabular}{|l|l|}
\hline \multirow{4}{*}{ Fecundidade } & V.1. Ausência de Gestantes \\
\cline { 2 - 2 } & V.2. Ausência de Mães Amamentando \\
\cline { 2 - 3 } & V.3. Ausência de Crianças (o-6 anos) \\
\cline { 2 - 2 } & V.4. Ausência de Crianças/Adolescentes (0-14 anos) \\
\cline { 2 - 2 } & $\begin{array}{l}\text { V.5. Ausência de Crianças / Adolescentes /Jovens (0-17 } \\
\text { anos) }\end{array}$ \\
\hline Atenção e cuidados especiais & V.6. Ausência de Portadores de Deficiência \\
\cline { 2 - 2 } com idosos & V.7. Ausência de Idoso \\
\hline \multirow{2}{*}{ Dependência econômica } & $\begin{array}{l}\text { V.8. Mais da Metade dos Membros têm Idade Ativa (16- } \\
66 \text { anos) }\end{array}$ \\
\hline \multirow{3}{*}{ Presença da mãe } & $\begin{array}{l}\text { V.9. Não existe criança no domicílio que a mãe tenha } \\
\text { morrido }\end{array}$ \\
\cline { 2 - 2 } & $\begin{array}{l}\text { V.10. Não existe criança no domicílio que não viva com } \\
\text { a mãe }\end{array}$ \\
\hline
\end{tabular}

Fonte: ASPF (2011).

O índice de acesso ao ensino-IE é composto pelas variáveis analfabetismo e escolaridade e será calculado pela fórmula:

$I E=\left[(E 1+E 2) / 2+\left(E_{3}+E_{4}+E_{5}\right) / 3\right] / 2$

Sendo,

Quadro 2. Indicadores de Acesso ao Ensino

\begin{tabular}{|l|l|}
\hline \multirow{2}{*}{ Analfabetismo } & E.1. Ausência de Adulto Analfabeto (idade igual o maior de 18 anos \\
\cline { 2 - 3 } & E.2. Ausência de Adulto Analfabeto Funcional \\
\hline \multirow{3}{*}{ Escolaridade } & E.3. Presença de pelo menos um adulto com fundamental completo \\
\cline { 2 - 2 } & E.4. Presença de pelo menos um adulto com ensino médio completo \\
\cline { 2 - 3 } & E.5. Presença de pelo menos um adulto com alguma educação superior \\
\hline
\end{tabular}

Fonte: ASPF (2011).

O índice de acesso ao conhecimento profissional e tradicional - IC é composto pelas variáveis: qualificação profissional e habilidade especial e será 
Desenvolvimento rural e agricultura familiar: um estudo do Projeto de Assentamento Dirigido Humaitá - Porto Acre (AC)

calculado pela fórmula:

$I C=\left(C_{1}+C_{2}+C_{3}\right) / 3$

Sendo,

Quadro 3. Indicadores de Acesso ao Conhecimento Profissional e Tradicional

\begin{tabular}{|l|l|}
\hline \multirow{4}{*}{$\begin{array}{l}\text { Qualificação } \\
\text { profissional/habilidade } \\
\text { especial }\end{array}$} & $\begin{array}{l}\text { C.1. Presença de pelo menos um trabalhador com alguma } \\
\text { profissão ou habilidade especial }\end{array}$ \\
\cline { 2 - 2 } & $\begin{array}{l}\text { C.2. Presença de pelo menos um trabalhador com alguma } \\
\text { profissão ou habilidade especial que atue na área }\end{array}$ \\
\cline { 2 - 2 } & $\begin{array}{l}\text { C.3. Presença de pelo menos um trabalhador com algum } \\
\text { treinamento ou capacitação }\end{array}$ \\
\hline
\end{tabular}

Fonte: ASPF (2011).

O índice de acesso ao trabalho-IT é composto pela variável disponibilidade de trabalho e será calculado pela fórmula:

$I T=(T 1+T 2+T 3) / 3$

Sendo,

Quadro 4. Indicadores de Acesso ao Trabalho

\begin{tabular}{|l|l|}
\hline \multirow{4}{*}{ Disponibilidade de Trabalho } & $\begin{array}{l}\text { T.1. Mais da metade dos membros em idade ativa encontra-se } \\
\text { ocupada }\end{array}$ \\
\cline { 2 - 3 } & $\begin{array}{l}\text { T.2. Todos os membros em idade ativa estão usando mais da } \\
\text { metade de sua disponibilidade de mão de obra na produção }\end{array}$ \\
\cline { 2 - 2 } & T.3. Ausência de assalariamento fora da UPF \\
\hline
\end{tabular}

Fonte: ASPF (2011).

O índice de disponibilidade de recurso -IR é composto pelas variáveis: pobreza e capacidade de geração de renda e será calculado pela fórmula:

$I R=(R 1+R 2+R 3) / 3$

Sendo,

Quadro 5. Indicadores de Disponibilidade de Recursos

\begin{tabular}{|l|l|}
\hline Extrema pobreza & $\begin{array}{l}\text { R.1. Renda familiar superior à 1/2 da linha de reprodução } \\
\text { familiar }\end{array}$ \\
\hline Pobreza & R.2. Renda familiar superior à linha de reprodução familiar \\
\hline $\begin{array}{l}\text { Capacidade de Geração de } \\
\text { Renda }\end{array}$ & $\begin{array}{l}\text { R.3. Maior parte da renda familiar não advém de } \\
\text { transferências }\end{array}$ \\
\hline
\end{tabular}

Fonte: ASPF (2011).

O índice de desenvolvimento infantil -ID é composto pelas variáveis: trabalho precoce, acesso e progresso escolar, mortalidade infantil, e será calculado pela fórmula: 
$I D=[(D 1+D 2) / 2+(D 3+D 4) / 2+(D 5+D 6) / 2+(D 7+D 8+D 9) / 3] / 4$

Sendo,

Quadro 6. Indicadores de Desenvolvimento Infantil

\begin{tabular}{|l|l|}
\hline \multirow{2}{*}{ Trabalho Precoce } & D.1. Ausência de criança de menos de 10 anos trabalhando \\
\cline { 2 - 2 } & D.2. Ausência de criança de menos de 14 anos trabalhando \\
\hline \multirow{2}{*}{ Acesso à escola } & D.3. Ausência de criança 7-14 anos fora da escola \\
\cline { 2 - 2 } & D.4. Ausência de criança 15-17 anos fora da escola \\
\hline \multirow{2}{*}{ Progresso escolar } & D.5. Ausência de adolescente de 10 a 14 anos analfabeto \\
\cline { 2 - 2 } & D.6. Ausência de jovem de 15 a 17 anos analfabeto \\
\hline \multirow{3}{*}{ Mortalidade infantil } & D.7. Ausência de mãe cujo filho tenha morrido \\
\cline { 2 - 2 } & D.8. Há, no máximo, uma mãe cujo filho tenha morrido \\
\cline { 2 - 2 } & D.9. Ausência de mãe com filho nascido morto \\
\hline
\end{tabular}

Fonte: ASPF (2011).

O índice de condições habitacionais (IH) é composto pelas variáveis: domicílio, acesso à água, esgoto, energia e bens duráveis e será calculado pela fórmula:

$\mathrm{IH}=\left[\mathrm{H}_{1}+\mathrm{H}_{2}+\mathrm{H}_{3}+\mathrm{H}_{4}+\mathrm{H}_{5}+\left(\mathrm{H}_{6}+\mathrm{H}_{7}+\mathrm{H}_{8}+\mathrm{H}_{9}\right) / 4\right] / 6$

Sendo,

Quadro 7. Indicadores de Condições Habitacionais

\begin{tabular}{|l|l|}
\hline Deficit habitacional & H.1. Densidade de até 2 moradores por cômodo \\
\hline $\begin{array}{l}\text { Acesso ao abastecimento de } \\
\text { água }\end{array}$ & H.2. Acesso adequado à água \\
\hline Acesso ao saneamento & H.3. Esgotamento sanitário adequado \\
\hline Acesso à coleta de lixo & H.4. Lixo é coletado \\
\hline Acesso à energia elétrica & H.5. Acesso à eletricidade \\
\hline \multirow{4}{*}{ Acesso aos bens duráveis } & H.6. Acesso ao fogão e à geladeira \\
\cline { 2 - 2 } & H.7. Acesso ao fogão, à geladeira, à televisão e ao rádio \\
\cline { 2 - 2 } & $\begin{array}{l}\text { H.8. Acesso ao fogão, à geladeira, à televisão, ao rádio e ao } \\
\text { telefone }\end{array}$ \\
\cline { 2 - 2 } & $\begin{array}{l}\text { H.9. Acesso ao fogão, à geladeira, à televisão, ao rádio, ao } \\
\text { telefone e ao computador }\end{array}$ \\
\hline \multirow{2}{*}{ Fonte: ASPF (2011). } &
\end{tabular}

O índice de condições ambientais (IA) é composto pelas variáveis: recursos hídricos, qualidade da água e destino de lixo e esgoto e será calculado pela fórmula:

$I A=\left[A 1+\left(A_{2}+A_{3}\right) / 2+\left(A_{4}+A_{5}\right) / 2\right] / 3$

Sendo, 
Desenvolvimento rural e agricultura familiar: um estudo do Projeto de Assentamento Dirigido Humaitá - Porto Acre (AC)

Quadro 8. Indicadores de Condições Ambientais

\begin{tabular}{|l|l|}
\hline Recursos hídricos & A.1. Presença de recursos hídricos \\
\hline \multirow{4}{*}{ Qualidade da água consumida } & $\begin{array}{l}\text { A.2. Presença de origem do abastecimento da água } \\
\text { consumida pela família }\end{array}$ \\
\cline { 2 - 2 } & $\begin{array}{l}\text { A.3. Presença de tratamento da água consumida pela } \\
\text { família }\end{array}$ \\
\hline \multirow{2}{*}{ Destino da água/esgoto } & A.4. Destino adequado da água servida \\
\cline { 2 - 2 } & A.5. Destino adequado do esgoto \\
\hline
\end{tabular}

Fonte: ASPF (2011).

\section{Resultados e discussões}

O PAD Humaitá foi criado em 1981, mediante um processo de reforma agrária promovida pelo INCRA, sendo um dos primeiros projetos de assentamentos instalado no Estado do Acre. Assim como outros assentamentos, foi apresentado como um projeto promissor que promoveria o desenvolvimento rural por meio da atividade agrícola, relacionada às características da agricultura familiar, condicionando um desenvolvimento sustentável efetivo para esse público.

O presente trabalho buscou analisar e comparar o índice de desenvolvimento rural das famílias assentadas no projeto, baseando-se nos levantamentos em dois períodos, sendo 2005/2006 e 2012/2013. Vale ressaltar que a metodologia disponível no período 1996/1997 subsidiava apenas a pesquisa econômica, portanto, não eram levantados aspectos sociais, inviabilizando a comparação desse período em relação aos demais somente com indicadores econômicos.

Durante a pesquisa, observou-se que várias famílias venderam seus lotes e saíram do PAD Humaitá. Processo ocasionou o aumento da concentração de terra na região para a prática de atividade pecuarista, fato que contraria a proposta de implantação dos projetos de assentamento de realizar uma reforma agrária, beneficiando famílias de produtores rurais com lotes de terras para extrair dela seu sustento, de forma que garantisse a reprodução social. Em conversas informais com produtores, observou-se um declínio de serviços prestados pela prefeitura, por exemplo, o transporte dos produtos agrícolas até o principal mercado municipal era ofertado pela instituição e deixou de ser oferecido. Além disso, alguns ramais no PAD Humaitá possuíam uma linha de transporte público que ligava à capital acreana, Rio Branco, porém, deixou de ser ofertada devido às condições intrafegáveis dos ramais, pela falta de manutenção que garantisse uma infraestrutura adequada para o tráfego de veículos pesados, como ônibus e caminhões.

É observado o declínio da produção familiar rural no PAD Humaitá a partir da análise do Gráfico 1. Percebe-se que produtos de subsistência, como arroz, macaxeira, milho e feijão, chamados por "lavoura branca", apresentam uma queda nos períodos estudados. No período de 1996/1997, verifica-se que essa produção chega a somar mais de $60 \%$ na geração de renda bruta no assentamento, garantindo também o autoconsumo das famílias, fato que favorece a atividade da agricultura familiar, uma vez que não apresenta dependência total do mercado para a obtenção de alimentos básicos. Porém, no período de 2005/2006, observa-se que a produção 
de arroz e feijão é apresentada timidamente, com um aumento da macaxeira e parcial do milho. Entretanto, no terceiro período, 2012/2013, a produção da lavoura branca apresenta uma queda preocupante, destacando a produção de arroz e feijão, que desaparecem das culturas que geram renda no PAD Humaitá, além de mostrar a especialização de produção no abacaxi, que dispara com $55 \%$ da geração de renda bruta.

Gráfico 1. Evolução da Geração de Renda Bruta no PAD Humaitá de culturas, em percentual, nos períodos 1996/1997, 2005/2006 e 2012/2013

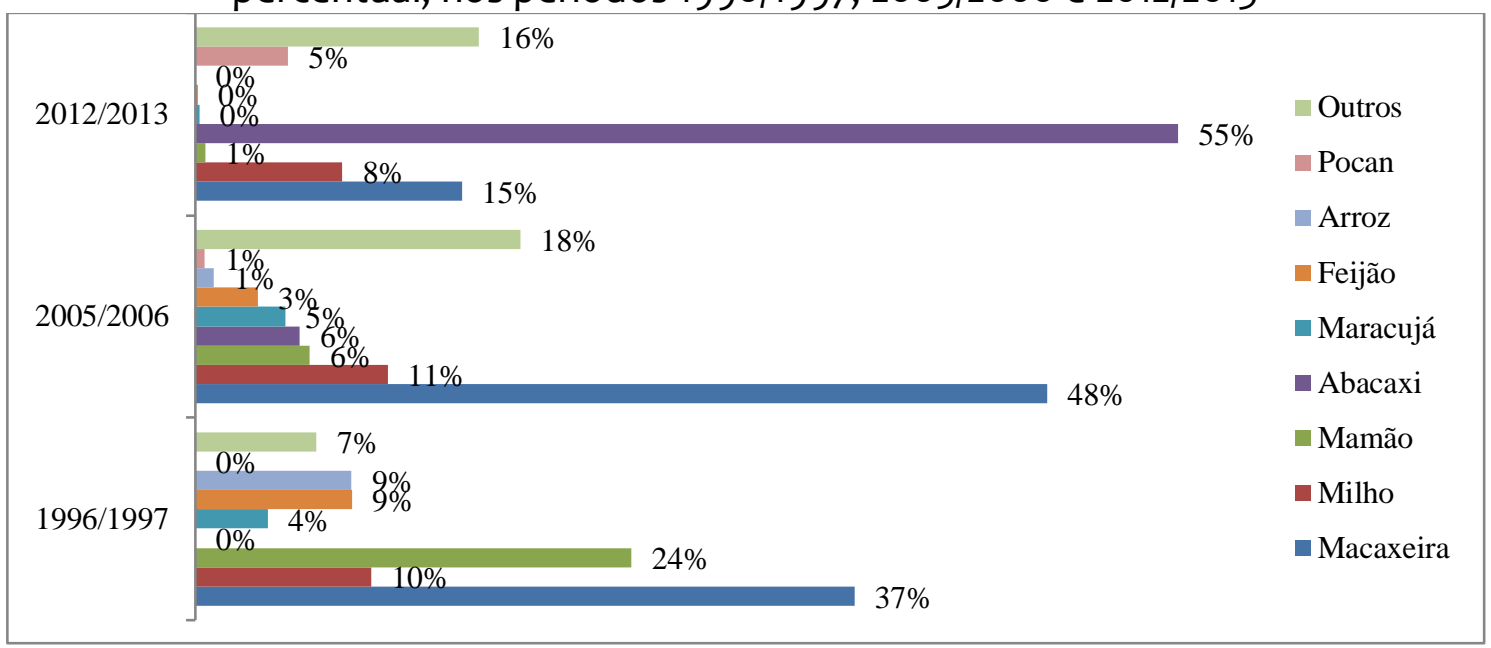

Fonte: ASPF (2014).

A partir do Gráfico 2, observa-se as criações que geram renda no PAD Humaitá, verificando um crescimento e especialização na produção de gado bovino, bem como a produção de leite e seus derivados. É importante destacar que a atividade pecuarista não favorece a agricultura familiar, uma vez que, para garantir a produção com viabilidade, são necessárias extensas áreas de terra, sendo o principal estorvo da produção familiar rural por não terem acesso a grandes áreas de terra.

Gráfico 1 - Evolução da Geração de Renda Bruta no PAD Humaitá de criações, em percentual, nos períodos 1996/1997, 2005/2006 e 2012/2013

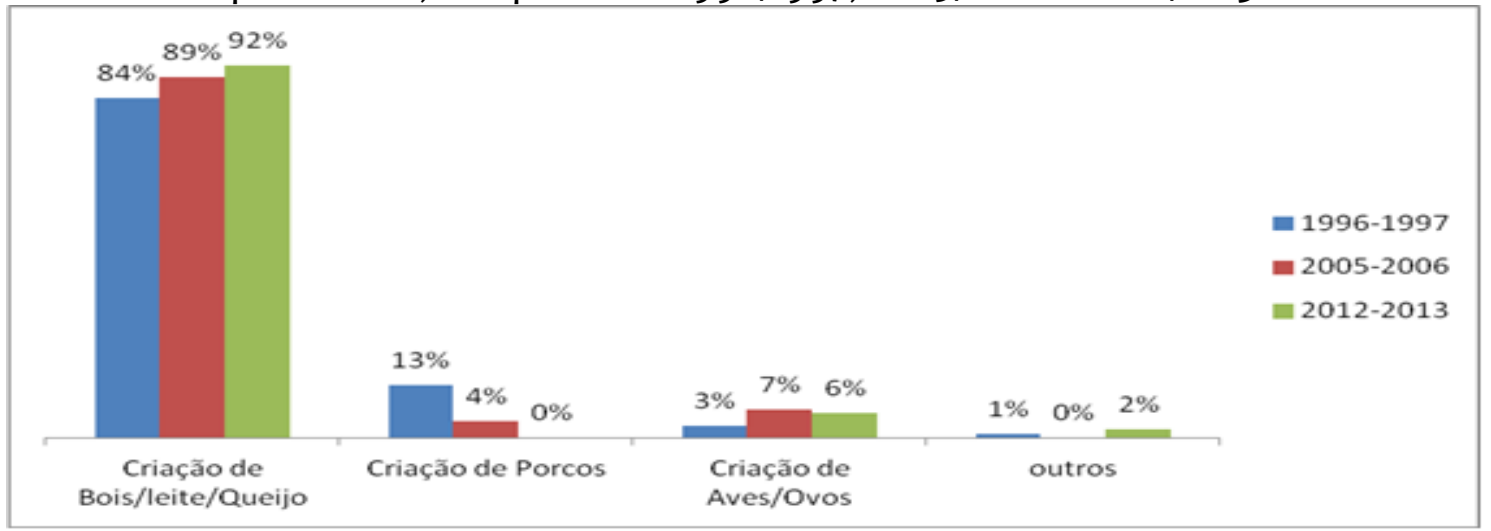

Fonte: ASPF (2014). 
Desenvolvimento rural e agricultura familiar: um estudo do Projeto de Assentamento Dirigido Humaitá - Porto Acre (AC)

Ao notar o grande aumento da produção pecuarista no PAD Humaitá, observa-se um grande problema para a produção familiar rural, uma vez que se trata da especialização de produção, como também de uma atividade inviável para agricultura familiar, o que é confirmado pela da Tabela 1.

Dessa forma, percebe-se uma situação preocupante no PAD Humaitá: a desapropriação da agricultura familiar do assentamento. Ao analisar a renda bruta na região, verifica-se uma queda constante. No período 1996/1997, é indicado uma geração de renda duas vezes maior que o salário mínimo-SM vigente no País. No segundo período, 2005/2006, esse valor reduz para 40\% acima do SM. Já no terceiro período, uma nova queda, passando para $23 \%$ acima do SM, mostrando uma tendência de falência desse setor na região.

Além disso, a relação entre a RB gerada e o custo total de produção indicada através do IEE, ao longo dos períodos analisados, apresentou uma grande queda. Enquanto no período de 1996/1997 esse indicador apresentava uma atividade altamente viável, no segundo período essa situação apresenta uma queda, chegando perto do empate entre renda e custo. Porém, no terceiro período, 2012/2013, é apresentada uma situação inviável no assentamento, mostrando a necessidade da elaboração de políticas públicas para alavancar novamente a agricultura familiar. Ademais, outro fator importante a destacar é a linha de dependência do mercado, mostrando uma relação maior com o mercado e tendência ao endividamento externos da família, uma vez que se trata de um valor acima dos indicadores que expressam o desempenho econômico das famílias.

Assim, nota-se a grande redução do autoconsumo na localidade, apresentando uma queda de $81 \%$ no período de 2012/2013 em relação a 1996/1997. Essa queda do autoconsumo está ligada ao grande crescimento do Bens e Serviços Comprados do Mercado-VBCC. Assim, as famílias no PAD Humaitá mostram uma inclinação à dependência do mercado, apresentando características contraditórias do perfil de um produtor familiar ao reduzir o que seria uma de suas fortalezas, enfraquecendo sua possibilidade de reprodução social no campo.

Tabela 1. Resultado Econômico nas Unidades Padrão Fiscal do PAD Humaitá, em valores medianos, nos períodos 1996/1997, 2005/2006 e 2012/2013

\begin{tabular}{lcccc}
\hline \multicolumn{1}{c}{ Indicadores Econômicos } & Unidade & $\mathbf{1 9 9 6 / 1 9 9 7 *}$ & $\mathbf{2 0 0 5 / 2 0 0 6 *}$ & $\mathbf{2 0 1 2 / 2 0 1 3}$ \\
\hline RB - Renda Bruta & R\$/mês & $1.793,75$ & $1.016,26$ & 888,23 \\
RL - Renda Líquida & R\$/mês & $1.547,28$ & 660,69 & 361,16 \\
MBF - Margem Bruta Familiar & R\$/mês & $1.585,65$ & 797,47 & 751,02 \\
CF - Custo Fixo & R\$/mês & 304,85 & 751,34 & $1.310,00$ \\
CV - Custo Variável & R\$/mês & 348,37 & 253,98 & 171,43 \\
VBCC - Bens e Serviços Comprados no & R\$/mês & 466,62 & 676,61 & 961,32 \\
Mercado & R\$/mês & 781,43 & $1.413,62$ & $2.271,33$ \\
LDM - Linha de Dependência do Mercado & R\$/mês & 947,75 & 175,43 & 177,75 \\
AC - Autoconsumo & R\$/mês & $2.400,39$ & $1.024,95$ & $1.393,49$ \\
NV - Nível de Vida & und. & 2,34 & 1,09 & 0,55 \\
IEE - Índice de Eficiência Econômica & und. & 0,89 & 0,88 & 0,96 \\
MBF/RB & R\$/dia & 107,16 & 107,54 & 19,69 \\
MBF/Qh/d & und. & 0,45 & 0,47 & 0,42 \\
GINI & & &
\end{tabular}

Fonte: ASPF (2014). 
O desempenho econômico das famílias no PAD Humaitá apresenta uma decadência preocupante para o assentamento, o que apresenta um grande estorvo para o desenvolvimento das famílias no assentamento.

O Gráfico 1 apresenta a comparação dos índices que compõe o IDF-R entre os períodos 2005/2006 e 2012/2013, bem como o próprio indicador responsável pela mensuração da situação da vida no campo.

Dessa forma, nota-se que no período de 2005/2006 o IDF-R apresenta uma boa situação de desenvolvimento no assentamento. No período de 2012/2013, esse índice ainda apresenta-se como uma boa situação, porém, mostra um cenário preocupante ao perceber uma queda em relação ao período anterior.

Ao comparar cada índice que compõe o IDF-R, verifica-se que apenas dois índices no segundo período, 2012/2013, apresentaram uma evolução positiva em relação ao período, 2005/2006. O índice de desenvolvimento infantil (ID), mostrando uma melhora no que diz respeito ao acesso das crianças ao ensino básico, como também a ausência de trabalho precoce na localidade; e o índice de acesso ao trabalho (IT), mostrando que as famílias possuem facilidade de alocar sua mão de obra, seja na própria agricultura familiar, como fora das UPFs, fato que foi constatado no assentamento.

Por outro lado, os demais índices apresentaram uma queda considerável, sendo seis índices. Em relação ao índice de acesso ao ensino (IE), percebe-se a necessidade de políticas educacionais voltadas às famílias do assentamento, observando que as famílias apresentaram uma decadência em relação ao nível de escolaridade, mostrando o aumento do número de analfabetos e analfabetos funcionais. Isso inviabiliza a implantação de programas de treinamentos e capacitações para a comunidade, fato que é confirmada através do índice de conhecimento profissional ou tradicional (IC), observando que esse índice sofreu uma queda, além de provocar no assentamento a inviabilidade econômica, dada a ausência de conhecimentos voltados para a atividade desempenhada.

Vale destacar que, entre as famílias do PAD Humaitá, foi notado que vários jovens ingressaram nas universidades, como também filhos de produtores que possuem formação de nível técnico e nível superior, porém, saíram do assentamento para morar na capital acreana, Rio Branco. Em um dos relatos, um produtor demonstrou preocupação por não saber o que será do seu lote futuramente, uma vez que seus filhos estão estudando e pretendem mudar do local.

Além disso, no índice de disponibilidade de recursos (IR) é observada a maior queda. Esse índice mostra a dificuldade que a agricultura familiar encontra em gerar renda no assentamento. Nota-se que é o menor índice em relação aos demais, o que implica rever algumas políticas de incentivo à produção, como já foi observado em períodos anteriores.

Em relação à infraestrutura da localidade, está expressa por meio do índice de condições habitacionais (IH), o qual também apresentou uma pequena queda no período de 2012/2013. Esse enfraquecimento relaciona-se às condições de acesso dos ramais no assentamento que não recebem a manutenção adequada para garantir a viabilidade, como também está atrelada a ausência de uma rede de esgoto em determinadas localidades. Assim, questões como essa afetam também 
Desenvolvimento rural e agricultura familiar: um estudo do Projeto de Assentamento Dirigido Humaitá - Porto Acre (AC)

no desempenho do índice de condições ambientais (IA), que também apresentou queda no período 2012/2013 e está diretamente relacionado a questões como o destino de resíduos sólidos no assentamento, podendo pensar em políticas de inserção do PAD Humaitá da coleta de resíduos pela prefeitura, tendo em vista que a localidade é próxima ao município.

Gráfico 3. Comparação do IDF-R no PAD Humaitá, Porto Acre - AC, nos períodos 2005/2006 e 2012/2013

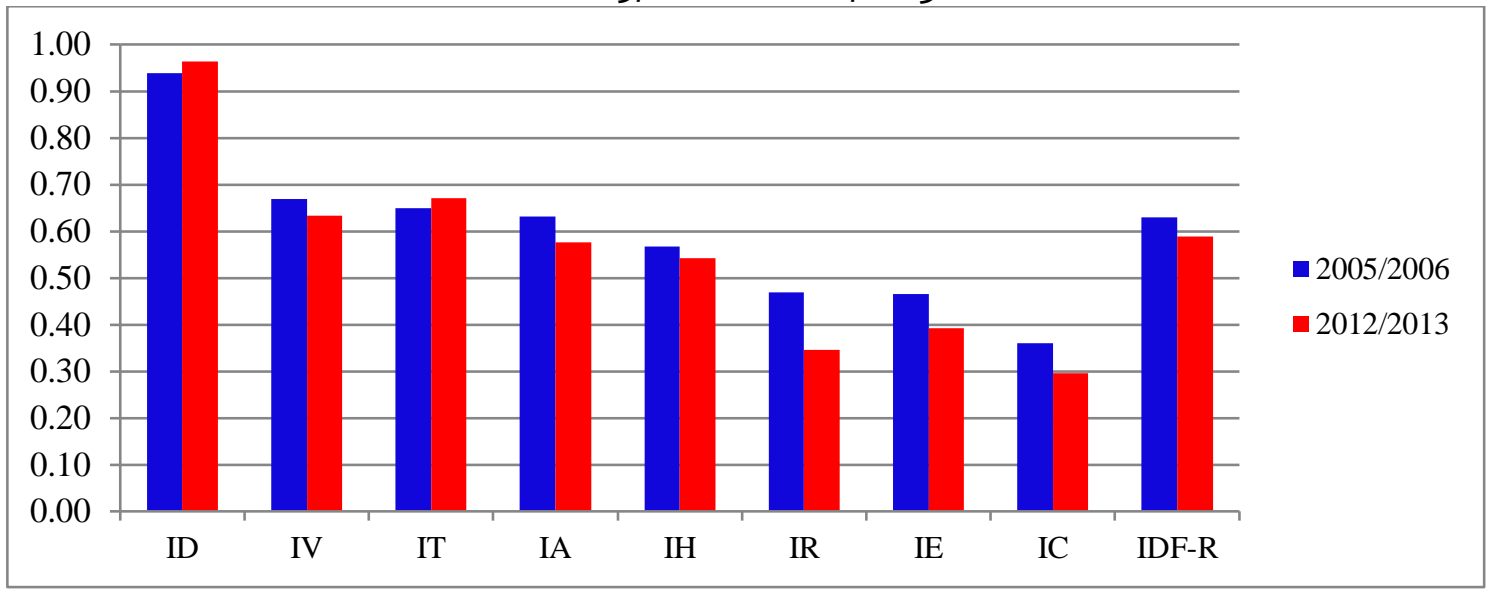

Fonte: ASPF (2014).

\section{Considerações finais}

$\mathrm{Na}$ década de 1970, o governo militar implantou as políticas desenvolvimentistas na Amazônia, o que desencadeou diversos impactos sociais, econômicos e ambientais, a partir da desapropriação de terras de várias famílias dessa região, incentivando, principalmente, a atividade pecuarista.

Dessa forma, na década seguinte o governo federal tenta reparar os danos causados pelas políticas de reforma agrária. Assim, com a criação do INCRA, são implantados os primeiros projetos de assentamento, como os PADs, principalmente na Amazônia, encaminhando uma melhoria de vida na região.

É nesse contexto que o PAD Humaitá é criado, de forma que as famílias beneficiadas tirariam da terra o seu sustento, auxiliando na reprodução social, além de promover o desenvolvimento rural na região.

Nesse sentido, o presente trabalho buscou avaliar e comparar a evolução do IDF-R no assentamento, com base em dois períodos, sendo 2005/2006 e 2012/2013, como também verificou o desempenho econômico das famílias com base nos períodos 1996/1997, 2005/2006 e 2012/2013.

A hipótese inicial indicava que esse desenvolvimento rural tão almejado não seria alcançado pelas UPFs do local nos períodos analisados devido às variações negativas de suas subdimensões, o que realmente foi comprovado. A retração do IDF-R corrobora a hipótese inicial deste trabalho, identificando que não existe avanço do desenvolvimento rural no PAD Humaitá. Esse índice é resultante de uma variação negativa de seis componentes em um universo de oito variáveis, sendo que as duas restantes estiveram num nível de estagnação.

Atrelando o desenvolvimento rural da região à situação econômica, percebe-se no período de 2005/2006 um desempenho favorável à atividade da 
agricultura familiar, apresentando uma geração de renda entre as famílias na localidade de $40 \%$ acima do SM vigente e um IDF-R de 0,63.

Porém, esse cenário é alterado ao analisar o período 2012/2013, verificando um desempenho econômico totalmente inviável à agricultura familiar, no qual é apresentado uma renda bruta de apenas $23 \%$ acima do SM vigente. Ademais, o IDF-R mostra-se em queda em relação ao período anterior, despertando a atenção para políticas que encaminhem adequadamente estas questões.

Além do aspecto econômico, é importante relatar o cenário encontrado no terceiro momento da pesquisa, 2012/2013, observando que várias famílias venderam seus lotes, formando-se várias fazendas em um projeto de assentamento de reforma agrária. Vale ressaltar que, nos primeiros assentamentos criados pelo INCRA, era dado aos beneficiados o título definitivo da terra, o que permite ao assentado a venda de sua propriedade. Para resolver essa questão, nos novos assentamentos criados foi alterada a modalidade de documentação entregue ao beneficiado. Atualmente, o documento ofertado é a concessão de uso da terra, impedindo a venda do lote.

Dessa forma, percebe-se a necessidade da elaboração de políticas públicas por intermédio das instituições da localidade voltadas à comunidade do PAD Humaitá, de forma que incentivem a produção, contendo a evasão do assentamento, bem como promover um efetivo desenvolvimento rural.

\section{REFERÊNCIAS}

ALVAREZ, Albino Rodrigues. Desenvolvimentos teóricos sobre distribuição de renda com ênfase em seus limites. 1996. 76f. Dissertação de mestrado. (Faculdade de Economia, Administração e Contabilidade) - Universidade de São Paulo, São Paulo (SP), 1996.

ASPF - Análise Socioeconômica de Sistemas Básicos de Produção Familiar Rural no Estado Acre. 2014. Disponível em: <http://aspf.wordpress.com>. (Projeto de Pesquisa do Centro de Ciências Jurídicas e Sociais Aplicadas da UFAC). 2014.

BARBOSA, Gisele Silva. O Desafio do Desenvolvimento Sustentável. Revista Visões,

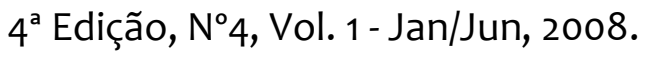

. Índice de Desenvolvimento Familiar Rural no Acre: uma aplicação da estatística multivariada. XLVI Congresso da SOBER. Rio Branco, Acre, Brasil. 2008.

BARROS, Ricardo Paes; HENRIQUES, Ricardo; MENDONÇA, Rosane. A Estabilidade Inaceitável: Desigualdade e Pobreza no Brasil. Texto para Discussão $n^{\circ} 800$. IPEA, Rio de Janeiro, 2001.

BRESSER-PEREIRA, Luiz Carlos. O processo histórico do desenvolvimento econômico. (Texto para Discussão EESP/FGV 157, dezembro 2006). Versão de 31 de maio de 2008. 
Desenvolvimento rural e agricultura familiar: um estudo do Projeto de Assentamento Dirigido Humaitá - Porto Acre (AC)

BRITO, Ana Paula Diniz. Reforma agrária, capital social e a gestão dos recursos naturais: caso do Projeto de Desenvolvimento Sustentável Bonal. 2013. 93f. Dissertação de mestrado. (Programa de Pós-Graduação em Desenvolvimento Regional) - Universidade Federal do Acre, Rio Branco (AC). 2013.

BUAINAIN, Antônio Márcio; MIRANDA, Carlos; TIBÚRCIO, Breno. A nova cara da pobreza rural: desafios para as políticas públicas. Brasília: IICA. (Serie desenvolvimento rural sustentável; v.16) 540 p. 2012.

CENTRO de Referência Virtual do Professor - SEE-MG. Setembro/2010.

COCA, Estevan Leopoldo de Freitas. Debatendo o conceito de reforma agrária: considerações sobre os tipos de assentamentos rurais no Brasil. CAMPOTERRITÓRIO: Revista de Geografia Agrária, v. 8, n. 16, p. 170-197. 2013.

COSTABEBER, José Antônio; CAPORAL, Francisco Roberto. Possibilidades e alternativas do desenvolvimento rural sustentável. In: Vela, Hugo. (Org.): Agricultura Familiar e Desenvolvimento Rural Sustentável no Mercosul. Santa Maria: Editora da UFSM/Pallotti, 2003.

FERNANDES, Ângela Esther Borges. O Perfil da Agricultura Familiar Brasileira. 2006. Disponível em: <http://www.webartigos.com/articles/16496/1/O-PERFIL-DAAGRICULTURA-FAMILIAR-BRASILEIRA/pagina1.html>. Acesso em: 21 maio 2011.

FILHO, Antônio Euzébios; GUZzO, Raquel Souza Lobo. Desigualdade social e pobreza: contexto de vida e de sobrevivência. Psicologia \& Sociedade. Pontifícia Universidade Católica de Campinas, Campinas, Brasil, 21 (1): 35-44, 2009.

FONSECA, Ana e FAGNANI, Eduardo. Políticas sociais, desenvolvimento e cidadania. São Paulo: Editora Fundação Perseu Abramo, 2013.

FURTADO, Celso. Os Desafios da Nova Geração. Revista de Economia Política, vol. $24, n^{\circ} 4$ (96), outubro-dezembro/2004.

HOFFMANN, Rodolfo. Distribuição de renda e crescimento econômico. Estudos Avançados. 15 (41), 2001.

INSTITUTO NACIONAL DE COLONIZAÇÃO E REFORMA AGRÁRIA (INCRA). Base de dados dos projetos de reforma agrária do Brasil. Brasília-DF. 2010.

INSTITUTO DE PESQUISAS ECONÔMICAS APLICADAS - IPEA. Definição e metodologia de cálculo dos indicadores e índices de desenvolvimento humano e condições de vida. Brasília-DF. 1998.

INSTITUTO DE PESQUISAS ECONÔMICAS APLICADAS - IPEA. Políticas Sociais Acompanhamento e Análise. Edição Especial. Brasília - DF. 2013. 
KAGEYAMA, Ângela. Desenvolvimento Rural: Conceito e Medida. Cadernos de Ciência \& Tecnologia, Brasília, v. 21, n. 3, p. 379-408, set./dez. 2004.

LIMA JUNIOR, Francisco Bezerra de. Agricultura Familiar e suas Relações de Mercado: Um Estudo Sobre a Formação de Preços do Palmito de Pupunha do PDS Bonal. 2013. 108f. Dissertação de mestrado (Programa de Pós Graduação em Desenvolvimento Regional) - Universidade Federal do Acre, Rio Branco (AC), 2013.

MACIEL, Raimundo Cláudio Gomes (coord.) Diagnóstico socioeconômico dos sistemas básicos de produção familiar rural do estado do Acre (ASPF) - período 1996/2006. Rio Branco, Acre, Brasil: EDUFAC, 2010.

NAVARRO, Zander. Desenvolvimento rural brasileiro: os limites do passado e os caminhos do futuro. Estudos Avançados 15 (43), 2001.

OLALDE, Alicia Ruiz; PORTUGAL, Cadja Araújo. Agricultura Familiar, Reforma Agrária e sua inserção no enfoque territorial no Brasil. Trabalho apresentado no XLII Congresso da Sociedade Brasileira de Economia e Sociologia Rural, Cuiabá-MT, 2004.

PLEIN, C. e FILIPPI, E. E. O Programa Aquisição de Alimentos da Agricultura Familiar (PAA): geração de renda e segurança alimentar. Revista Faz Ciência, v. 14, p. 1-18, 2012.

PROGRAMA DAS NAÇÕES UNIDAS PARA O DESENVOLVIMENTO. Relatório do Desenvolvimento Humano 2002. Aprofundar a democracia num mundo fragmentado. Lisboa-Portugal, 2002.

ROCHA, Sônia. Pobreza e indigência no Brasil: algumas evidências empíricas com base na PNAD 2004. Revista Nova Economia. Minas Gerais. 2006.

SANTOS, Luiz Augusto de Faria dos; DULCl, João de Assis. Distribuição de renda no Brasil e linha de pobreza: diferentes realidades para diferentes conceitos. XVI Encontro Nacional de Estudos Populacionais, realizado em Caxambu- MG - Brasil, de 29 de setembro a 03 de outubro de 2008.

SCHNEIDER, Sérgio. Situando o desenvolvimento rural no Brasil: o contexto e as questões em debate. Revista de Economia Política, vol. 30, no 3 (119), pp. 511-531, julho-setembro/2010.

SIMOURA. Flávia Alves. A agroindustrialização como estratégia de reprodução social da agricultura familiar: um estudo no Projeto de Desenvolvimento Sustentável Bonal. 2013. 105f. Dissertação de mestrado (Programa de Pós Graduação em Desenvolvimento Regional) - Universidade Federal do Acre, Rio Branco (AC), 2013.

UVB, Faculdade on-line. Aula Nº 10 - Pobreza e Distribuição de Renda, 2009. 
Desenvolvimento rural e agricultura familiar: um estudo do Projeto de Assentamento Dirigido Humaitá - Porto Acre (AC)

VILELA, Elaine Meire. Módulo Didático: Desigualdade social: permanência e evolução no Brasil. Currículo Básico Comum - Sociologia do Ensino Médio. 2010.

WEISHEIMER, Nilson. Desenvolvimento rural, capitalismo e agricultura familiar. Olhares Sociais (02) janeiro-junho de 2013: 51-78.

Raimundo Cláudio Gomes Maciel. Economista, Doutor em Economia Aplicada (UNICAMP) e Professor do Centro de Ciências Jurídicas e Sociais Aplicadas da Universidade Federal do Acre (CCJSA/UFAC).rcgmaciel@ufac.br

Reginaldo Silva Mariano. Economista. Mestre em Desenvolvimento Regional (2014) pelo Programa de Pós-Graduação da Universidade Federal do Acre. MBA em Gestão com Ênfase em Controle Externo pela UNINTER (2011). reginaldoms@hotmail.com

Pedro Gilberto Cavalcante Filho. Economista, Pesquisador do Projeto Análise Socioeconômica dos Sistemas Básicos de Produção Familiar Rural do Estado do Acre (ASPF/CCJSA/UFAC). pedro.gilberto@hotmail.com 